\title{
Correction to: Validation trial for efficacy of ultrasonographic measurement method to predict ascitic volume using virtual ultrasonography
}

\author{
Masashi Hirooka ${ }^{1}$. Yohei Koizumi ${ }^{1}$. Yusuke Imai ${ }^{1} \cdot$ Atsushi Yukimoto $^{1} \cdot$ Takao Watanabe $^{1} \cdot$ Osamu Yoshida $^{1}$. \\ Masanori Abe ${ }^{1} \cdot$ Yoichi Hiasa ${ }^{1}$
}

Published online: 1 August 2019

(c) The Japan Society of Ultrasonics in Medicine 2019

\section{Correction to: \\ Journal of Medical Ultrasonics (2018) 45:555-564 https://doi.org/10.1007/s10396-018-0879-9}

In the original publication of the article the formula under the heading "Three-point method" was incorrect, the correct formula is given in this correction.

$(1100 / 3) \times(A+B+0.5 \times C)$.
Publisher's Note Springer Nature remains neutral with regard to jurisdictional claims in published maps and institutional affiliations.

The original article can be found online at https://doi.org/10.1007/ s10396-018-0879-9.

Yoichi Hiasa

hiasa@m.ehime-u.ac.jp

1 Department of Gastroenterology and Metabology, Ehime

University Graduate School of Medicine, Shitsukawa, Toon,

Ehime 791-0295, Japan 